8. Naber KG. Treatment options for acute uncomplicated cystitis in adults. J Antimicrob Chemother 2000; 46:23-7.

9. Ronald AR, Harding GK. Complicated urinary tract infections. Infect Dis Clin North Am 1997; I I:583-92.

10. Fihn SD. Clinical practice. Acute uncomplicated urinary tract infection in women. N Engl J Med 2003; 349:259-66.

I I. Stamm WE, Norrby SR. Urinary tract infections: disease panorama and challenges. JInfect Dis 200 I; I83:(Suppl I): SI-4.

12. Warren JW. Catheter-associated urinary tract infections. Infect Dis Clin North Am 1997; I I:609-22.

13. Pewitt EB, Schaeffer AJ. Urinary tract infection in urology, including acute and chronic prostatitis. Infect Dis Clin North Am 1997; I I:623-46.

14. Barnes RC, Daifuku R, Roddy RE, Stamm WE. Urinary-tract infection in sexually active homosexual men. Lancet I986; I: I 7 | -3.

I5. Spach DH, Stapleton AE, Stamm WE. Lack of circumcision increases the risk of urinary tract infection in young men. JAMA I 992; 267:679-8I.

16. Pinho AM, Lopes GS, Ramos-Filho CF, Santos O da R, Oliveira MP, Halpern M, et al. Urinary tract infection in men with AIDS. Genitourin Med I 994; 70:30-4.

17. Bishara J, Leibovici L, Huminer D, Drucker M, Samra Z, Konisberger H, et al. Five-year prospective study of bacteraemic urinary tract infection in a single institution. Eur J Clin Microbiol Infect Dis I 997; I 6:563-7.
18. Gupta K, Hooton TM, Stamm WE. Increasing antimicrobial resistance and the management of uncomplicated community-acquired urinary tract infections. Ann Intern Med 200 I; I 35:4 I-50.

19. Carton JA, Gomez Moro MB, Gonzalez Lopez B, Maradona JA, de Diego I, et al. Nosocomially acquired infection of the urinary tract. Enferm Infecc Microbiol Clin I 989; 7:408-I 4.

20. Orenstein R, Wong ES. Urinary tract infections in adults. Am Fam Physician 1999; 59: I225-34.

21. Nicolle LE. Asymptomatic bacteriuria in the elderly. Infect Dis Clin North Am 1997; II:647-62.

22. Mohammad M, Mahdy ZA, Omar J, Maan N, Jamil MA. Laboratory aspects of asymptomatic bacteriuria in pregnancy. Southeast Asian JTrop Med Public Health 2002; 33:575-80.

23. Rushton HG. Urinary tract infections in children: epidemiology, evaluation, and management. Pediatr Clin North Am 1 997; 44: I I 33-69.

24. Kaplan DM, Rosenfield AT, Smith RC. Advances in the imaging of renal infection: helical CT and modern coordinated imaging. Infect Dis Clin North Am 1997; 1 1:68I-705.

25. Patterson TF, Andriole VT. Detection, significance, and therapy of bacteriuria in pregnancy: update in the managed health care era. Infect Dis Clin North Am 1997; I I:593-608.

\section{VIDEOTORACOSCOPIA NO TRATAMENTO DE EXCELÊNCIA DO EMPIEMA DA INFÂNCIA}

\section{Sr. Editor}

Em relação à $R A M B$, meus parabéns. Ótimos artigos e excelentes comentários, particularmente a seção "À beira do leito". Quanto ao Panorama Internacional "A videotoracoscopia constitui tratamento de excelência do empiema da infância?" - RAMB 2004, 50 (4):349-62, em nome da cirurgia pediátrica de meu hospital, eu não poderia deixar de tecer alguns comentários. O Dr. Uenis Tannuri aborda um artigo de Gates et al. (J Pediatr Surg 2004, 39:38 I -6) sobre o valor da videotoracoscopia no tratamento dos empiemas pleurais na criança. Acredito que o estudo ainda não tenha, efetivamente, fechado a polêmica em torno do assunto. Após revisar 44 artigos científicos, os autores não puderam realizar meta-análise para concluir qual é o melhor método de tratamento do empiema pleural na criança, sendo que a única vantagem da videotoracoscopia foi a redução do tempo de internação hospitalar. Nossa experiência em I 43 videotoracoscopias para tratamento desta afecção leva à conclusão semelhante, particularmente no que tange à redução do custo final do tratamento.

\section{Comentário do autor}

Este assunto é, de fato, polêmico. A conduta mais conservadora, não-invasiva, em empiemas pleurais na criança deve ser a primeira escolha. $O$ tratamento cirúrgico pode ser indicado apenas em fases mais tardias, quando não se consegue boa evolução do paciente com a simples drenagem pleural. Nestes casos, muito raros (em torno de $2 \%$ ), pode ocorrer associadamente necrose e destruição do parênquima pulmonar, que implicarão na necessidade de ressecção do segmento comprometido. Quanto às pleuras e à cavidade por elas delimitada, a drenagem do pus e tratamento com antibióticos apropriados são habitualmente eficazes.

O estudo fecha a polêmica do valor limitado da videotoracoscopia no tratamento do empiema. Deve-se levar em conta os riscos da videotoracoscopia (anestesia geral e o procedimento em si, particularmente hemorragias). O tempo de internação hospitalar perde significado diante dos custos envolvidos com o procedimento. Outro fato importante é que nem todos os hospitais dispõem do equipamento para videocirurgia, e nem todos os cirurgiões estão habilitados para executar o método. Finalmente, há que se considerar que crianças não são arrimos de família e, portanto, os argumentos do período de internação hospitalar e impossibilidade de retorno ao trabalho não se aplicam a elas.

Uenis Tannuri São Paulo - SP 